\title{
Incidência da Síndrome de Burnout em docentes do ensino superior no noroeste do Rio Grande do Sul
}

O objetivo deste artigo é identificar a incidência da Síndrome de Burnout no trabalho em docentes de instituições de ensino superior. Burnout é aquilo que deixa de funcionar por falta de energia, ou seja, uma pessoa que não tem mais um bom desempenho físico e mental, que produz desgaste progressivo da relação do sujeito com sua atividade profissional. Trata-se de uma pesquisa descritiva tipo survey, com abordagem quantitativa e qualitativa dos dados. Os sujeitos da pesquisa foram 67 docentes de instituições de ensino superior no noroeste do Estado Rio Grande do Sul. O instrumento de pesquisa foi o Maslach Burnout Inventory Educators Survey (MBI-ED). Identificou-se que os docentes não apresentam burnout, mas 51,31\% apresentam tendência ao seu desenvolvimento. As evidências contribuem para definição de ações estratégicas na área de gestão humana de pessoas nas instituições de ensino superior específicas ao grupo de docentes.

Palavras-chave: Síndrome de Burnout; Trabalho docente; Esgotamento profissional.

\section{Incidence of Burnout Syndrome in higher education teachers in northwestern Rio Grande do Sul}

\begin{abstract}
The aim of this article is to identify the incidence of Burnout Syndrome at work in teachers of higher education institutions. Burnout is what stops working because of lack of energy, that is, a person who no longer has a good physical and mental performance, which causes progressive wear of the subject's relationship with his professional activity. It is a survey descriptive research, with quantitative and qualitative approach of the data. The research subjects were 67 teachers from higher education institutions in the northwestern state of Rio Grande do Sul. The research instrument was the Maslach Burnout Inventory Educators Survey (MBIED). It was identified that the teachers did not present burnout, but $51.31 \%$ presented a tendency to their development. The evidence contributes to the definition of strategic actions in the area of human management of people in higher education institutions specific to the group of teachers.
\end{abstract}

Keywords: Burnout Syndrome; Teaching work; Professional exhaustion.

Topic: Recursos Humanos

Reviewed anonymously in the process of blind peer.

Vanessa Hasper Dessbesell

Universidade Regional do Noroeste do Estado do Rio Grande do Sul, Brasil http://lattes.cnpq.br/9549578702544759

vanessahasper@hotmail.com

\section{Adriane Fabricio}

Universidade Regional do Noroeste do Estado do Rio Grande do Sul, Brasil http://lattes.cnpq.br/9275057052526069

adriane.fabricio@unijui.edu.br

\section{Martinho Luís Kelm (iD}

Universidade Regional do Noroeste do Estado do Rio Grande do Sul, Brasil http://lattes.cnpq.br/2798758797454828

http://orcid.org/0000-0002-4004-1574

martinho@unijui.edu.br

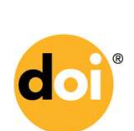

DOI: 10.6008/CBPC2179-684X.2018.002.0005
Received: 15/05/2018

Approved: 22/07/2018
Referencing this:

DESBESELL, V. H.; FABRICIO, A.; KELM, M. L.. Incidência da Síndrome de Burnout em docentes do ensino superior no noroeste do Rio Grande do Sul. Revista Brasileira de Administração Científica, v.9, n.2, p.50-61, 2018. DOI: http://doi.org/10.6008/CBPC2179$\underline{684 X .2018 .002 .0005}$ 


\section{INTRODUÇÃO}

A profissão de docência pode, ao mesmo tempo, conduzir a situações de enriquecimento e satisfação no trabalho e ocasionar ou incrementar fatores de estresse no trabalho e, se persistentes, podem levar a síndrome de burnout. Esta síndrome em docentes está sendo considerado um problema social contemporâneo e vem sendo estudada em diversos países por produzir danos pessoais, organizacionais e sociais (CARLOTTO, 2010). Os primeiros estudos sobre síndrome de burnout surgiram em meados nos anos 1970 nos Estados Unidos e mais tarde (década de 1990) no Brasil (MASLACH et al., 2001). Sob a perspectiva social psicológica preconizada por Christina Maslach, os aspectos individuais associados às condições e relações de trabalho contribuíram para a definição dos construtos de burnout, que são: exaustão emocional, despersonalização e reduzida realização profissional.

Este artigo tem por objetivo verificar a incidência da síndrome de burnout em docentes de instituições de ensino superior. Com base na identificação do perfil sociodemográfico dos docentes, buscase verificar a incidência da exaustão emocional, despersonalização, reduzida realização no trabalho, as quais operam como dimensões da síndrome de burnout. O estudo é relevante no contexto contemporâneo e brasileiro tendo em vista que os docentes do ensino superior tiveram seus tempos de trabalho reduzidos em favor da realização de atividades burocráticas e baseadas no produtivismo (metas), que produziu conflitos de papéis, invasão do espaço privado e aumentou a preocupação com o desempenho acadêmico ao mesmo tempo em que ser verifica o aumento dos casos de incidência de burnout neste grupo social.

Os resultados do estudo são apresentados em quatro partes além desta introdução. No referencial teórico é apresentado o estado da arte da síndrome de burnout. Na segunda parte são apresentados os procedimentos metodológicos do estudo empírico. Nas terceiras e quarta partes constam os dados empíricos e as análises, bem como as conclusões.

\section{REVISÃO TEÓRICA}

\section{Síndrome de Burnout}

Maslach et al. (2001) aponta que os primeiros artigos sobre síndrome de burnout surgiram em meados dos anos 1970, nos Estados Unidos, e sua principal contribuição foi descrever o fenômeno, atribuirIhe um nome e mostrar que não era uma resposta incomum. As experiências com pessoas que trabalhavam em serviços humanos e de cuidados de saúde serviram como base para o início dos estudos. Os primeiros escritos são de Freudenberger, em 1975, um psiquiatra que trabalhava em uma clínica de cuidados de saúde, e de Maslach, em 1976, psicóloga social que estava estudando as emoções no local de trabalho.

Burnout, no jargão popular inglês, é aquilo que deixou de funcionar por falta de energia, ou seja, uma pessoa que não tem mais um bom desempenho físico ou mental (TRIGO et al., 2007). Limongi-França et al. (2012) o descrevem como um estado que produz desgaste progressivo da relação do sujeito com sua atividade profissional. Harrison (1999), por sua vez, entende síndrome de burnout como resultado do estresse crônico típico do ambiente de trabalho que produz situações de excessiva pressão emocional 
associada ao intenso envolvimento com pessoas por longos períodos de tempo, conflitos, poucas recompensas emocionais e reconhecimento.

Os primeiros estudos foram concentrados em profissionais das áreas humanas, serviços e educação, porém, o autor admite que outros profissionais, além dos que trabalham diretamente na assistência aos demais, estão susceptíveis ao burnout. Sendo assim, a partir da década de 1990 as pesquisas empíricas continuaram estendendo o conceito de burnout para outras categorias profissionais como escritórios, informática, militares, gerentes (BENEVIDES-PEREIRA, 2010; MASLACH et al., 2001).

Ao longo de seu processo de construção, tem sido abordada sob quatro perspectivas teóricas baseadas na possível causa da síndrome: clínica, sócio psicológica, organizacional e sócio histórica. A concepção mais utilizada dos estudos atuais é a sócio psicológica, preconizada por Christina Maslach, que a partir de seus estudos, pontuou ser o ambiente laboral, a base das variáveis produtoras de burnout. Este modelo destaca a importância das características do trabalho como fator causador de burnout, constituído por três dimensões: exaustão emocional, despersonalização e baixo sentimento de realização profissional (BENEVIDES-PEREIRA 2010; TRIGO et al., 2007; CARLOTTO, 2010).

A primeira dimensão, exaustão emocional (EE), o profissional acaba sentindo-se esgotado, com pouca energia para o desenvolvimento do trabalho, a impressão que ele tem é que as energias não serão recuperadas. Destaca-se que em função das relações em situações de trabalho e da intensa carga emocional que o contato intenso com pessoas impõe, o indivíduo pode desenvolver exaustão emocional. Também profissionais que apresentam grandes expectativas em relação ao seu desenvolvimento profissional e não alcançam o retorno esperado (LIMONGI-FRANÇA et al., 2012).

A exaustão emocional é a característica central e mais óbvia, sendo o aspecto mais minunciosamente analisado, no entanto, o fato da exaustão ser condição necessária para caracterizar a síndrome não significa que ela é suficiente, pois não se consegue capturar aspectos críticos da relação das pessoas com o seu trabalho, nesta dimensão o indivíduo acaba se distanciando emocionalmente como forma de lidar com a sobrecarga de trabalho (MASLACH et al., 2001).

A segunda dimensão, despersonalização (DE), para Maslach et al. (2001) é a forma de se afastar do destinatário do serviço, desenvolvendo uma indiferença ou atitude cínica quando se está esgotado e desanimado, afastar ou distanciar é uma reação imediata ocorrendo assim uma forte relação de exaustão e despersonalização. Completando este pensamento Schaufeli et al. (2013) afirma que o cinismo em relação ao trabalho e aos colegas é uma atitude de autoproteção, porém, não é uma proteção suficiente para equilibrar a saúde mental, podendo tal atitude criar mais problemas, agravando o sentimento de exaustão, estresse e cansaço.

Na visão de Limongi-França et al. (2012), a despersonalização desenvolve um distanciamento emocional exacerbado, frieza, indiferença, insensibilidade e postura desumanizada diante das necessidades dos outros. Não significa que o indivíduo deixou de ter sua personalidade, mas que esta sofreu ou vem sofrendo alterações com os usuários de seus serviços, alunos, pacientes, cliente etc. (MASLACH et al., 1996). 
A terceira dimensão, reduzida realização profissional (rPR), evidencia o sentimento de insatisfação, tendência a avaliar-se negativamente principalmente em relação ao seu trabalho com os clientes, insatisfação em relação a si próprio e com as realizações no trabalho, desmotivação, baixa eficiência no trabalho (MASLACH et al., 1996). Os motivos que levam a exaustão e despersonalização colaboram para o sentimento de reduzida realização, é difícil ter uma sensação de realização quando se sente esgotado ou quando se sente indiferente com relação às pessoas. Enquanto a falta de realização surge a partir de uma falta de recursos expressivos, a exaustão e a despersonalização decorrem da sobrecarga de trabalho e de conflitos sociais (MASLACH et al., 2001).

De maneira geral, a maioria dos autores está de acordo que o burnout é uma resposta a cronificação de um processo de estresse característico do meio laboral, também como síndrome psicológica de esgotamento, cinismo e ineficácia, trazendo consequências negativas tanto em nível individual, como profissional e organizacional. Na esfera organizacional acomete-se por perda de rendimento produtivo e na baixa qualidade do serviço executado, no aumento do absenteísmo, na alta rotatividade, em acidentes ocupacionais, resultando em prejuízos financeiros. Na esfera profissional os efeitos são, atendimento negligente, lentidão, contato impessoal, cinismo (BENEVIDES-PEREIRA, 2003; LEITER et al., 2004; BENEVIDESPEREIRA, 2010).

À medida que se reconhece a importância de propiciar melhores condições laborais, surge investigações que podem embasar as modificações necessárias para que tais condições se instalem (BENEVIDES-PEREIRA, 2003). O profissional em seu ambiente organizacional vivencia constantemente situações de estresse, porém cada indivíduo responde a estas situações de maneira diferente, dependendo de fatores organizacionais, individuais, laborais e sociais, quando os níveis de tensão, ansiedade, perfeccionismo e competitividade são altos, o risco de desenvolver sofrimento psíquico, estresse, depressão, burnout - são maiores (TRIGO et al., 2007). Limongi-França et al. (2012) destaca que o burnout é considerado um dos desdobramentos mais importantes do stress profissional, o que impõe sua apresentação em qualquer estudo que pretende abordar a relação de stress e trabalho

Complementando, Carlotto (2010) considera importante diferenciar conceitualmente burnout de estresse para não o confundir. $O$ estresse tem um caráter geralmente agudo, transitório e não necessariamente negativo ou relacionado à situação de trabalho. Devido às consequências, tem crescido a perspectiva de se investigar e se investir na qualidade de vida do trabalhador, passando o burnout ser protagonista no mundo laboral na medida em que veio a explicitar grande parte das consequências do impacto das atividades ocupacionais no trabalhador e deste na organização. Para enfrentar são necessárias intervenções preventivas e curativas no ambiente de trabalho, além, de ações específicas para o tratamento e reabilitação dessas pessoas (BENEVIDES-PEREIRA, 2010; SCHAUFELI et al., 2013).

\section{Síndrome de Burnout em docentes}

Em decorrência da transformação social nos últimos anos, tem aumentado as responsabilidades e exigências sobre os educadores, a fim de atender às expectativas da sociedade que se encontra em processo 
de mudança constante, modificando o papel do professor (CARLOTTO, 2010). Segundo Esteve (1999), talvez a mais significativa modificação ocorrida no papel do professor está relacionada ao 'avanço contínuo do saber', onde o contexto social exige dos professores uma responsabilização por novas funções, não bastando apenas conhecimento, mas também habilidades pessoais, provocando tensões e desorientações quando as mudanças são excessivas e num período curto de tempo.

Na visão de Cunha (1989) o professor além de dominar a matéria do ensino, deve integrá-lo com o contexto curricular e histórico social, utilizando métodos de ensinos variados, dominando a linguagem corporal/gestual e ainda buscar a efetiva participação do aluno em aula. Para Carlotto (2010) a ocorrência do burnout em professores é considerada atualmente um problema social de extrema relevância e vem sendo estudada em diversos países, devido aos danos individuais, organizacionais e sociais. A síndrome em docentes interfere no ambiente educacional, quanto à obtenção dos objetivos pedagógicos, desencadeando um processo de desumanização e apatia e a intenção de abandonar a profissão de docência (GUGLIELMI et al., 1998).

As manifestações da Síndrome, conforme Farber (1991) são divididas em individuais e profissionais, no aspecto individual em geral os professores sentem-se emocionalmente e fisicamente exaustos, irritados, ansiosos, com raiva ou tristes, levando a frustrações emocionais causando insônia, úlcera, dores de cabeça, hipertensão, uso de álcool e medicamentos, conflitos familiares e sociais.

No aspecto profissional, o planejamento de aula torna-se menos frequente e cuidadoso, apresentando perda de entusiasmo, sentindo menos simpatia pelos alunos e menos otimismo quanto à avaliação de seu futuro, sentindo-se frustrado pelos problemas que venham ocorrer em sala de aula, pela falta de progresso do conhecimento de seus alunos, desenvolvendo distanciamento com relação a estes. Chegando a avaliar sua profissão como algo sem valor, se arrependendo de ter escolhido e pensando em deixar de exercer tal profissão (FARBER, 1991).

Kyriacou (1989) já apontava sete principais fontes de estresse para os professores referenciado por Pedrabissi et al. (1991), os quais são: desmotivação dos alunos no desempenho escolar; mau comportamento dos alunos; falta de oportunidade na carreira, baixos salários, falta de equipamentos para o ensino, número elevado de alunos em sala de aula; pressão de tempo e prazos; baixo reconhecimento social da profissão; conflitos entre colegas e supervisores; e mudanças rápidas e adaptação de currículos. Na medida em que se entende melhor o burnout pode-se prevenir, atenuar ou estancar através de ações de enfrentamento, possibilitando o professor prosseguir concretizando seus projetos de vida pessoal e profissional, em busca da melhor qualidade de vida, refletindo em sua vida e todos os envolvidos no sistema educacional (CARLOTTO, 2002).

\section{METODOLOGIA}

Visando responder ao objetivo deste estudo, empreendeu-se um estudo de cunho quantitativo, descritivo, do tipo survey, tendo por base uma amostra aleatória por conveniência com 67 profissionais que desempenham funções de docência em IES do noroeste do Estado do Rio Grande do Sul. Os profissionais que 
fazem parte do estudo atuam em diferentes organizações públicas e privadas, desempenhando funções de docência, e docência com cargo de gestão. Durante o período de coleta de dados, a aplicação do instrumento foi empreendida por meio de questionários virtuais (Google Docs).

O questionário aplicado constitui-se num modelo teórico, o Maslach Burnout Inventory Educators Survey (MBI-ED), desenvolvido e validado na literatura. A ele, somam-se questões para identificar o perfil dos respondentes; trata-se de um instrumento composto por 22 afirmativas, estruturado e dividido em 3 fatores relacionadas entre si, mas independentes: Exaustão Emocional (EE), Despersonalização (DE) e Realização Profissional (RP). É um questionário autoaplicável, do tipo Likert de 7 pontos que variam de 0-6. Considerase em burnout uma pessoa que revele altas pontuações em EE e DE, associadas a baixos valores em RP.

Após a tabulação dos dados, os mesmos passaram por análise estatística pelo software SPSS, versão 21. As análises estatísticas realizadas compreendem, análise descritiva simples (frequência, médias e desviopadrão). A fim de verificar a confiabilidade dos instrumentos, ou seja, o grau de consistência interna entre os indicadores de um fator aplicou-se o alpha de cronbach. Conforme Field (2009), valores entre $0,7 \leq \alpha<0,8$ representam índices aceitáveis, $0,8 \leq \alpha<0,9$, representam um bom índice e $>0,9$, diz respeito a um ótimo índice de Alfa de Cronbach, sendo que valores < 0,6 indicam escala não confiável.

\section{RESULTADOS E DISCUSSÕES}

\section{Perfil da amostra}

O perfil da amostra é composto por docentes do gênero feminino $(57,89 \%)$, casados/união estável $(69,70 \%)$, na faixa etária entre 25 a 45 anos $(52,64 \%)$, conforme a tabela 1 . A maioria dos participantes do estudo foi admitida na instituição educacional no período de 2011 a 2016. Segundo a tabela 2, 60,50\% dos docentes não ocupam cargos de gestão e 50,02\% realizam uma carga horária média de 40 horas. $\mathrm{Na}$ sequência, após realizar essa etapa do trabalho, que visou caracterizar o perfil dos docentes, passa-se para a discussão do Alfa de Cronbach do instrumento e seus constructos, análises descritivas simples (frequências, médias e desvios-padrão).

Tabela 1: Caracterização geral do perfil da amostra.

\begin{tabular}{|c|c|c|c|}
\hline Variáveis & Alternativas & Frequência & Percentual (\%) \\
\hline \multirow{3}{*}{ Ano de admissão na instituição } & Entre 1970 a 1980 & 5 & $6,57 \%$ \\
\cline { 2 - 4 } & Entre 1981 a 1990 & 8 & $10,52 \%$ \\
\cline { 2 - 4 } & Entre 1991 a 2000 & 11 & $14,48 \%$ \\
\cline { 2 - 4 } & Entre 2001 a 2010 & 20 & $26,32 \%$ \\
\cline { 2 - 4 } & Entre 2011 a 2016 & 32 & $42,11 \%$ \\
\hline \multirow{2}{*}{ Gênero } & Feminino & 34 & $57,89 \%$ \\
\cline { 2 - 4 } & Masculino & 20 & $26,11 \%$ \\
\hline \multirow{2}{*}{ Faixa etária } & 25 a 35 anos & 20 & $26,32 \%$ \\
\cline { 2 - 4 } & 36 a 45 anos & 18 & $23,68 \%$ \\
\cline { 2 - 4 } & 46 a 55 anos & 13 & $23,68 \%$ \\
\cline { 2 - 4 } & mais de 55 anos & 53 & $17,10 \%$ \\
\hline \multirow{2}{*}{ Estado civil } & Solteiro (a) & 9 & $69,70 \%$ \\
\cline { 2 - 4 } & Casado (a)/União estável & $11,80 \%$ \\
\cline { 2 - 4 } & Separado(a)/Divorciado(a) & $1,30 \%$ \\
\cline { 2 - 4 } & Viúvo & & \\
\cline { 2 - 4 }
\end{tabular}


Tabela 2: Caracterização da amostra: cargo de gestão e carga horária.

\begin{tabular}{|c|c|c|c|}
\hline Variáveis & Alternativas & Frequência & Percentual (\%) \\
\hline Possui cargo de gestão na instituição & Não & 46 & $60,50 \%$ \\
\cline { 2 - 4 } & Sim & 30 & $39,50 \%$ \\
\hline Carga horária média de atividade na instituição & 4 horas & 1 & $1,31 \%$ \\
\cline { 2 - 4 } & 10 horas & 6 & $7,89 \%$ \\
\cline { 2 - 4 } & 20 horas & 11 & $14,47 \%$ \\
\cline { 2 - 4 } & 28 horas & 3 & 3,94 \\
\cline { 2 - 4 } & 32 horas & 17 & $22,37 \%$ \\
\cline { 2 - 4 } & 40 horas & 38 & $50,02 \%$ \\
\hline
\end{tabular}

\section{Análise da Síndrome de Burnout e suas dimensões}

A fim de apresentar as incidências das dimensões da síndrome de burnout na amostra, foi aplicado o instrumento MBI-ED, estruturado em 22 afirmativas que utilizam a escala Likert de sete pontos, onde zero representa que 'nunca apresentou tal sentimento' a seis que 'o tem todos os dias' para mensurar as três dimensões da síndrome de burnout: exaustão emocional, despersonalização e reduzida realização profissional. A tabela 3 apresenta a estatística descritiva da amostra, apresentando média e desvio padrão da dimensão 'exaustão emocional'. Benevides-Pereira (2010) aponta que a exaustão está ligada ao esgotamento físico e mental, a perda de energia para realizar as atividades, de ter chegado ao limite das possibilidades.

Tabela 3: Estatística descritiva da dimensão exaustão emocional.

\begin{tabular}{|c|l|c|c|}
\hline Questão & \multicolumn{1}{|c|}{ Exaustão Emocional } & Média & $\begin{array}{c}\text { Desvio } \\
\text { Padrão }\end{array}$ \\
\hline $\mathbf{1 4}$ & Sinto que estou trabalhando em demasia. & 3,46 & 1,61 \\
\hline $\mathbf{2}$ & Sinto-me cansado/a ao final de um dia de trabalho. & 3,40 & 1,49 \\
\hline $\mathbf{6}$ & Trabalhar com pessoas o dia todo me exige um grande esforço. & 2,82 & 1,62 \\
\hline $\mathbf{8}$ & Meu trabalho deixa-me exausto/a. & 2,63 & 1,37 \\
\hline $\mathbf{1}$ & Sinto-me esgotado/a emocionalmente por meu trabalho. & 2,61 & 1,26 \\
\hline $\mathbf{3}$ & $\begin{array}{l}\text { Quando me levanto pela manhã e vou enfrentar outra jornada de trabalho, sinto-me } \\
\text { cansado/a. }\end{array}$ & 2,28 & 1,31 \\
\hline $\mathbf{1 6}$ & Trabalhar diretamente com pessoas causa-me estresse & 2,19 & 1,51 \\
\hline $\mathbf{2 0}$ & Sinto que atingi o limite de minhas possibilidades. & 2,17 & 1,55 \\
\hline $\mathbf{1 3}$ & Sinto-me frustrado/a em meu trabalho. & 1,98 & 1,13 \\
\hline Média Geral & $\mathbf{2 , 6 1}$ & $\mathbf{1 , 4 2}$ \\
\hline
\end{tabular}

A dimensão de exaustão emocional apresentou uma média de 2,61, e desvio padrão de 1,42. Que, levando em consideração a escala de respostas pode ser considerado baixo. A tabela 4 apresenta a estatística descritiva da amostra, apresentando média e desvio padrão para a dimensão 'despersonalização'. Na visão de Limongi-França et al. (2012) a despersonalização desenvolve um distanciamento emocional exacerbado, frieza, indiferença, insensibilidade e postura desumanizada diante das necessidades dos outros. A dimensão despersonalização (DP) apresentou uma média de 2,24 e um desvio padrão de 1,45 que, levando em consideração a escala de respostas, pode ser considerado baixo.

Tabela 4: Estatística descritiva da dimensão despersonalização.

\begin{tabular}{|c|l|c|c|}
\hline Questão & \multicolumn{1}{|c|}{ Despersonalização } & Média & Desvio Padrão \\
\hline $\mathbf{1 1}$ & Preocupa-me o fato de que este trabalho esteja me endurecendo emocionalmente. & 2,49 & 1,63 \\
\hline $\mathbf{1 0}$ & Tenho me tornado mais insensível com as pessoas desde que exerço esse trabalho. & 2,37 & 1,63 \\
\hline $\mathbf{1 5}$ & Não me preocupo realmente com o que ocorre com alguns alunos. & 2,37 & 1,56 \\
\hline $\mathbf{2 2}$ & Sinto que os alunos me culpam por alguns de seus problemas. & 2,06 & 1,31 \\
\hline $\mathbf{5}$ & Creio que trato alguns alunos como se fossem objetos impessoais. & 1,91 & 1,16 \\
\hline Média Geral & $\mathbf{2 , 2 4}$ & $\mathbf{1 , 4 5}$ \\
\hline
\end{tabular}


As questões 'creio que trato algumas pessoas como se fossem objetos impessoais' ou 'não me preocupo com o que ocorre com alguns alunos', podem causar um impacto, pois encontram em desacordo com o que se espera de um bom profissional, sendo difícil para a própria pessoa que responde ao questionário, assumir suas atitudes no trabalho (BENEVIDES-PEREIRA, 2010). Os aspectos da terceira dimensão, realização profissional, encontram-se na tabela 5.

Tabela 5: Estatística descritiva da dimensão realização profissional.

\begin{tabular}{|c|l|c|c|}
\hline Questão & \multicolumn{1}{|c|}{ Realização Profissional } & Média & Desvio Padrão \\
\hline $\mathbf{1 9}$ & Tenho conseguido muitas realizações em minha profissão. & 4,75 & 1,13 \\
\hline $\mathbf{9}$ & Sinto que influencio positivamente a vida de outros através do meu trabalho. & 4,73 & 1,21 \\
\hline $\mathbf{1 8}$ & Sinto-me estimulado/a depois de trabalhar em contato com os alunos. & 4,68 & 1,16 \\
\hline $\mathbf{7}$ & Lido de forma eficaz com os problemas dos alunos. & 4,65 & 1,31 \\
\hline $\mathbf{4}$ & Posso entender com facilidade o que sentem meus alunos. & 4,60 & 1,31 \\
\hline $\mathbf{1 7}$ & Posso criar facilmente uma atmosfera relaxada para os meus alunos. & 4,34 & 1,36 \\
\hline $\mathbf{2 1}$ & Sinto que sei tratar de forma adequada os problemas emocionais no meu trabalho. & 4,25 & 1,41 \\
\hline $\mathbf{1 2}$ & Sinto-me com muita vitalidade. & 4,18 & 1,40 \\
\hline Média Geral & $\mathbf{4 , 5 2}$ & $\mathbf{1 , 2 8}$ \\
\hline
\end{tabular}

A dimensão realização profissional apresentou uma média de 4,52, e desvio padrão de 1,28, devido aos escores de realização profissional da amostra ser altos, pode ser considerado que estes docentes estão realizados em seu trabalho ou envolvidos com seu trabalho. Do ponto de vista teórico, Schaufeli et al. (2003) destaca que o EE e DP afiguram-se como os principais sintomas do Burnout. Estas dimensões representam o componente energético e interpessoal, respectivamente, sendo a síndrome representada pelo polo negativo destas duas dimensões. Em contrapartida, Maslach et al. (1999) aponta, em seu estudo, que o (RP) possui relação inversa com as outras duas dimensões (EE e DP).

Analisando os índices obtidos, considera-se que, conforme o modelo de burnout de Maslach et al. (1986), a exaustão é a primeira dimensão a surgir, como indicativo da síndrome, e esta, neste grupo, evidencia índice médio de 2,61 que pode ser considerado indicativo de um nível de burnout não significativo. A segunda dimensão do modelo de burnout diz respeito à despersonalização, a qual obteve índice médio de 2,24, representando também, indicativo de nível baixo. Por fim, a realização profissional apresentou um valor da média de 4,52, considerado valor alto, demonstrando alta realização profissional da amostra em seu trabalho. Quanto aos desvios padrão, no geral e por item, foram baixos, variando de 1,13 a 1,63, indicando pouca variabilidade na opinião dos respondentes.

Para se calcular a média de uma escala Likert, conforme Lopes (2016), é preciso esclarecer o nível atingido por cada conjunto de variáveis, a padronização destes escores permite a qualificação da soma dos resultados em medidas classificatórias, podendo ser transformado em três categorias, que são elas: baixa, média ou intermediária e alta. Seguindo este conceito, para mensuração dos níveis de burnout, são definidos como baixo, médio e alto. Considera-se em burnout uma pessoa que revele altas pontuações em EE, DE, associados a baixos valores em RP conforme Schaufeli et al. (2002), neste sentido não se pode avaliar as dimensões separadamente, mas é possível, através do gráfico 1, observar em que nível está a porcentagem da amostra. 


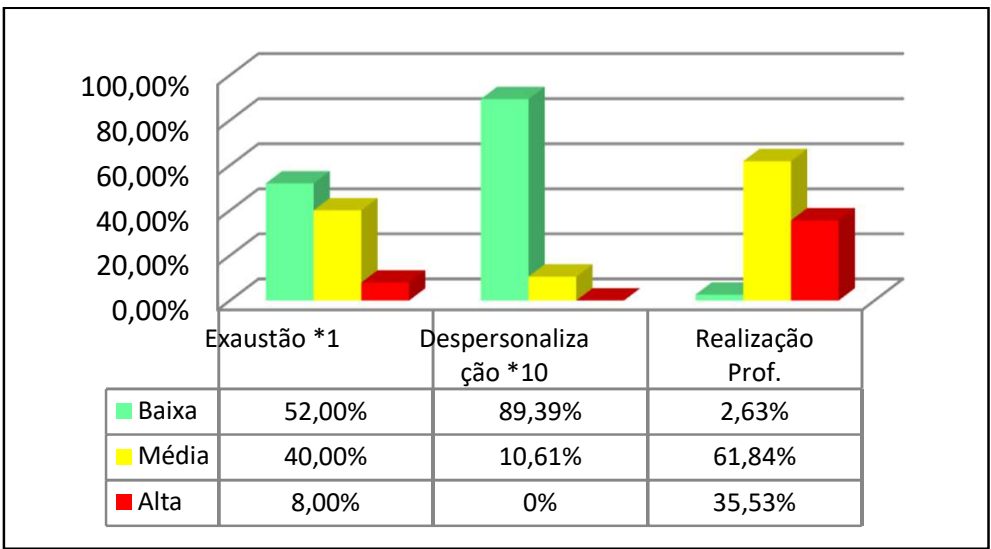

Gráfico 1: Nível de incidência das dimensões de burnout na amostra. Legenda: (*) Nunca apresentou.

Verifica-se que, na primeira dimensão, que apenas $8 \%$ estão com nível alto de exaustão emocional, que está associada à sobrecarga de trabalho, esgotamento crônico e tensão. A segunda dimensão, observase que apenas 10,61\% estão com nível médio de despersonalização que se acomete por uma atitude indiferente, onde o indivíduo perde o interesse e o significado pelo trabalho. Na terceira dimensão percebese que apenas 2,63\% estão com baixa RP, nesta dimensão a maioria está com médio índice de realização profissional. No gráfico 2 constam os resultados gerais da incidência de burnout nos participantes do estudo.

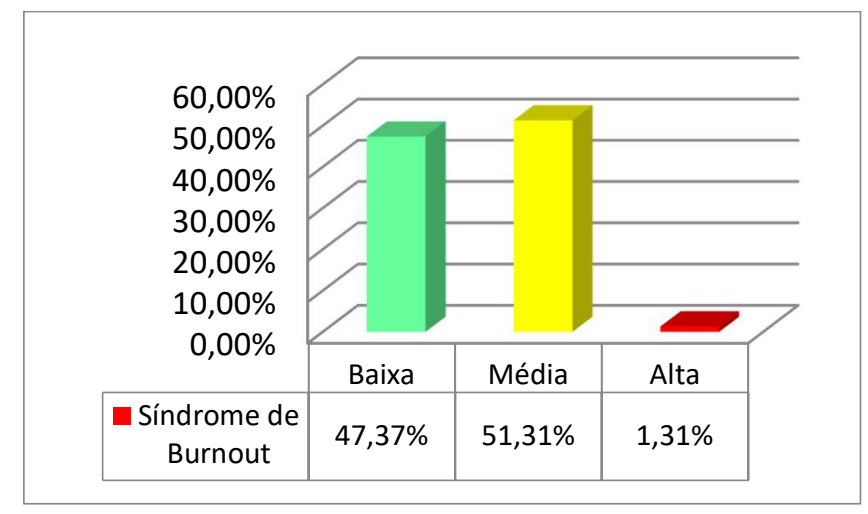

Gráfico 2: Nível de burnout na amostra.

O gráfico 2 apresenta classificado em baixa, média e alta as três dimensões de burnout agrupadas, sendo assim, da amostra 47,37\% está com baixo índice, 51,31\% estão com médio indicativo, o que significa que podem estar desenvolvendo e apenas 1,31\% apresentam a síndrome de burnout. Tendo em vista os resultados obtidos, considera-se que, a amostra em questão não apresenta a síndrome de burnout, pois segundo Schaufeli et al., (2002), uma vez que, médias baixas de exaustão e despersonalização, e altas de realização profissional, não representam indicativos de burnout.

Mesmo com os resultados encontrados, onde a amostra em questão não apresenta a síndrome de burnout, é importante destacar que o burnout é uma experiência individual específica do contexto do trabalho, instalando-se silenciosa e progressivamente, corroendo a relação do sujeito com sua atividade profissional e já foi regulamenta no Brasil através da a Lei no 3048/99 que reconhece a síndrome de esgotamento profissional como doença do trabalho (MASLACH et al., 2001; BENEVIDES-PEREIRA, 2010; LIMONGI-FRANÇA et al., 2012). Portanto, é imprescindível que seja avaliado também cada colaborador de 
modo individual. Essa afirmação da autora deste estudo pode ser reforçada a partir da transcrição das respostas dos docentes quando perguntados 'Para você a docência é estressante?' (Tabela 6).

Tabela 6: Docência estressante

\begin{tabular}{|c|c|c|c|}
\hline & Alternativas & Frequência & Percentual (\%) \\
\hline Para você, a profissão de docência é estressante? & Não & 30 & $39,47 \%$ \\
\cline { 2 - 4 } & Sim & 23 & $30,26 \%$ \\
\cline { 2 - 4 } & Talvez & 23 & $30,26 \%$ \\
\hline
\end{tabular}

Quando questionados se a docência é estressante 39,47\% (30) acham que a profissão de docência não é estressante, e 30,26\% (23) consideram a profissão de docência estressante e 30,26\% (23) afirmam que 'talvez' a profissão da docência é estressante. A maioria dos entrevistados acha que a profissão de docência não é estressante, mas há um número muito significativo de entrevistados que considera que a docência 'talvez' seja estressante. Se for agrupado as respostas "não" e "talvez", pode-se dizer que, para a maioria dos respondentes desta amostra, à docência é estressante, e os principais motivos destacados são: pouco tempo de preparo das aulas, exigência de atualização constante, sobrecarga de atividades além da docência, cobranças institucionais, burocracia, falta de interesse dos alunos nas disciplinas ministradas.

Todas as profissões têm seus prós e contras, mas a sobrecarga de atividades que acaba ocupando o final de semana dos docentes é muito preocupante, podendo o agrupamento e sobrecarga levar a síndrome de burnout, conforme mencionado por Maslach et al. (2001), em uma das dimensões, a exaustão, o indivíduo acaba se distanciando emocionalmente como forma de lidar com a sobrecarga de trabalho. A exaustão refere-se a sentimentos de tensão, esgotamento, fadiga crônica resultante de sobrecarga de trabalho (MASLACH et al., 1996). Na tabela 7, os resultados referem-se ao desejo de mudar de profissão.

Tabela 7: Desejo de mudar de profissão.

\begin{tabular}{|c|c|c|c|}
\hline & Alternativas & Frequência & Percentual (\%) \\
\hline Se você tivesse oportunidade de mudar de profissão, você mudaria? & Não & 61 & $80,26 \%$ \\
\cline { 2 - 4 } & Sim & 6 & $7,89 \%$ \\
\cline { 2 - 4 } & Talvez & 9 & $11,84 \%$ \\
\hline
\end{tabular}

Conforme demonstrado na tabela 7, quanto ao desejo de mudar de profissão 80,26\% (61) afirmam não ter desejo de mudar de profissão, os docentes em dúvida se mudariam de profissão correspondem a 11,89\% (9), já os docentes convictos de que se tivessem oportunidade mudariam de profissão, corresponder a 7,89\% (6) da amostra. Este resultado corrobora com o estudo de Garcia e Benevides-Pereira (2003) realizado com professores universitários da rede privada de Maringá- PR, no qual constatou que 74,68\% não tinham intenção de mudar de profissão.

De maneira geral observando as respostas, os motivos que levariam os docentes a mudar de profissão é a pressão por produtividade, aulas noturnas, trabalho nos finais de semana e se conseguissem outro trabalho com melhor remuneração mudariam de profissão. Mesmo assim a maioria dos entrevistados não mudaria de profissão, pois estão satisfeitos com a profissão e carreira e se realizam com as atividades. Para verificar a confiabilidade ou o grau de consistência interna entre os indicadores de um fator, aplicou-se o alpha de cronbach. Conforme Field (2009), valores entre $0,7 \leq \mathrm{a}<0,8$ representam índices aceitáveis, entre $0,8 \leq \mathrm{a}<0,9$, diz respeito a um bom índice e $>0,9$ diz respeito a um ótimo índice de alpha de cronbach; por 
sua vez, valores $<$ 0,6 indicam escala não confiável (FIELD, 2009). A Tabela 8 apresenta o alpha de cronbach da amostra.

Tabela 8: Alpha de cronbach.

\begin{tabular}{|c|c|c|}
\hline Fatores & Variáveis & Alpha de cronbach \\
\hline Exaustão & $1,2,3,6,8,13,14,16$ e 20 & 0,880 \\
\hline Despersonalização & $5,10,11,15$ e 22 & 0,612 \\
\hline Realização Profissional & $4,7,9,12,17,18,19,21$ & 0,780 \\
\hline \multicolumn{2}{|r|}{} & 0,711 \\
\hline
\end{tabular}

Na tabela 8 consta que, tomando por base os valores do alpha de cronbach $(\mathrm{EE}=\alpha$ de 0,$88 ; \mathrm{DE}=\alpha$ de $0,61$; e RP $=\alpha$ de 0,78 ; geral $\alpha=0,71)$, as três dimensões apresentam boa associação. Tal afirmação tem por base as análises realizadas por Maslach et al. (1996), que considerou as propriedades psicométricas do MBI, cujos coeficientes alfas de cronbach foram aceitáveis com os seguintes valores: $\mathrm{EE}=\alpha$ de 0,$90 ; \mathrm{DE}=\alpha$ de 0,79 ; e RP $=\alpha$ de 0,71 . Porém, o valor de alpha sofre mudanças conforme a população na qual se aplica a escala (FIELD, 2009).

Conforme Benevides-Pereira (2010), investigações em outros países, com outras populações, não tem encontrado resultados desta magnitude, e dentre as dimensões a despersonalização é a que mais tem sido questionada. É o caso da amostra em estudo que não atingiu a consistência interna de outras amostras, e a despersonalização ficou abaixo do esperado, mesmo assim o alpha total apresentou uma consistência considerada aceitável conforme determina os parâmetros estatísticos.

\section{CONSIDERAÇÕES FINAIS}

Ao findar este estudo, observou-se primeiramente que a amostra pesquisada, não apresenta indicativos da presença da síndrome, segundo critérios estabelecidos por Schaufeli et al. (2002), uma vez que, médias baixas de exaustão e despersonalização, e altas de realização ou envolvimento no trabalho, não representam indicativos de burnout. No caso deste estudo, verificou-se que da amostra $47,37 \%$ está com baixo índice, 51,31\% estão com médio indicativo e apenas 1,31\% apresentam a síndrome de burnout.

Quando analisadas as relações entre o perfil sócio demográfico com os fenômenos de burnout, não foram encontradas relações fortes entre os construtos, visto que, não apenas a idade, estado civil ou gênero podem desencadear o burnout, mas também variáveis como a personalidade, as características do trabalho, características organizacionais e características sociais, neste aspecto sugere-se aprofundar através de estudos a relação entre perfil e os fenômenos.

Apesar de ser um estudo quantitativo, a generalização dos achados não pode ser estendida aos demais profissionais do estado ou mesmo do Brasil, em função das diferenças e também da estrutura e cultura das organizações. Como sugestão de estudos futuros, indica-se a replicação desse estudo em outros contextos.

Os resultados obtidos neste estudo apoiam fortemente a prática da gestão de pessoas nas organizações que, por sua vez, precisa também investir nos seus colaboradores criando um clima de relacionamento de amizade, otimismo e confiança dentro do ambiente de trabalho ao verificar que a 
síndrome de burnout exerce influência sobre o bem-estar no trabalho. Este trabalho teve como objetivo primordial contribuir à área de pesquisa do campo do comportamento organizacional, ampliando os conhecimentos sobre o fenômeno que vem se sobressaindo na gestão de pessoas.

\section{REFERÊNCIAS}

BENEVIDES-PEREIRA, A. M. T.. Burnout: quando o trabalho ameaça o bem-estar do trabalho. 4 ed. São Paulo: Casa do Psicólogo, 2010.

BENEVIDES-PEREIRA, A. M. T.. O estado da arte do burnout no Brasil. InterAção Psy, v.1, n.1, p.4-11, 2003.

CARLOTTO, M. S.. A síndrome de burnout e o trabalho docente. Psicologia em Estudo, Maringá, v.7, n.1, p.21-29, 2002.

CARLOTTO, M. S.. Síndrome de burnout e satisfação no trabalho: um estudo com professores universitários. In: BENEVIDES-PEREIRA, A. M. T.. Burnout: quando o trabalho ameaça o bem-estar do trabalho. 4 ed. São Paulo: Casa do Psicólogo, 2010.

CUNHA, M. I.. O bom professor e sua prática. Campinas: Papirus, 1989.

ESTEVE, J. M.. O mal-estar docente: a sala de aula e a saúde dos professores. São Paulo: EDUSC, 1999.

FARBER, B. A.. Crisis in education. Stress and burnout in the American teacher. São Francisco: Jossey-Bass, 1991.

FIELD, A.. Discovering statistics using spss. 3 ed. London: Sage, 2009.

GARCIA, L. P.; BENEVIDES-PEREIRA, A. M. T.. Investigando o burnout em professores universitários. InterAção Psy, v.1, n.1, p.76-89, 2003.

GUGLIELMI, R. S.; TATROW, K.. Occupational stress, burnout, and health in teachers: a methodological and theoretical analysis. Review of Educational Research, v.68, n.1, p.61-69, 1998.

HARRISON, B. J.. Are you to burn out?. Fund Raising Management, v.30, n.3, p.25-28, 1999.
LEITER, M. P.; MASLACH, C.. Areas of worklife: a structured approach to organizational predictors of job burnout. Research in Occupational Stress and Well Being, v.3, p.91134, 2004.

LIMONGI-FRANÇA, A. C.; RODRIGUES, A. L.. Stress e trabalho: uma abordagem psicossomática. 4 ed. São Paulo: Atlas, 2012.

LOPES, L. F. D.. Métodos quantitativos. Santa Maria: UFSM, 2016.

MASLACH, C.; JACKSON, S. E.; LEITER, M. P.. Maslach Burnout Inventory. 3 ed. Palo Alto: Consulting Psychologists, 1996.

MASLACH, C.; LEITER, M. P.. Trabalho: fonte de prazer ou desgaste?. Campinas: Papirus, 1999.

MASLACH, C.; SCHAUFELI, W. B.; LEITER, M. P.. Job burnout. Annual Review of Psychology, v.52, p.397-422, 2001.

PEDRABISSI, L.; ROLLAND, J. P.; SANTINELLO, M.. Stress and burnout among teachers in Italy and France. The journal of psychology, v.127, n.5, p.529-535, 1991.

SCHAUFELI, W.; BAKKER, A.. UWES: Utrecht work engagement scale preliminary manual. Utrecht: HPUUU, 2003.

SCHAUFELI, W.; DIJKSTRA, P.; VAZQUEZ, A. C.. Engajamento no trabalho. São Paulo: Casa do Psicólogo, 2013.

SCHAUFELI, W.; SALANOVA, M.; GONZALES-ROMA, V.; BAKKER, A. B.. The measurement of engagement and burnout: a two sample confirmatory factor analytic approach. Journal of Happines Studies, v.3, p.71-92, 2002.

TRIGO, T. R.; TENG, C. T.; HALLAK, J. E. C.. Síndrome de burnout ou estafa profissional e os transtornos psiquiátricos. Revista de Psiquiatria Clínica, v.34, n.5, p.223-233, 2007.

A CBPC - Companhia Brasileira de Produção Científica (CNPJ: 11.221.422/0001-03) detém os direitos materiais desta publicação. Os direitos referem-se à publicação do trabalho em qualquer parte do mundo, incluindo os direitos às renovações, expansões e disseminações da contribuição, bem como outros direitos subsidiários. Todos os trabalhos publicados eletronicamente poderão posteriormente ser publicados em coletâneas impressas sob coordenação da Sustenere Publishing, da Companhia Brasileira de Produção Científica e seus parceiros autorizados. Os (as) autores (as) preservam os direitos autorais, mas não têm permissão para a publicação da contribuição em outro meio, impresso ou digital, em português ou em tradução. 